\title{
DEVELOPMENT AND VALIDATION OF LIQUID CHROMATOGRAPHIC METHOD FOR THE SIMULTANEOUS ESTIMATION OF EZETIMIBE AND LOVASTATIN IN HUMAN PLASMA
}

\author{
ISLAM ULLAH KHAN" ${ }^{a}$ TAYYABA KAUSAR ${ }^{a}$, MUHAMMAD ASHFAQ ${ }^{b *}$ AND SHAHZAD SHARIF
}

\author{
${ }^{a}$ Materials Chemistry Laboratory, Department of Chemistry, Faculty of Science and Technology, Government College University, Lahore-54000, Pakistan \\ ${ }^{b}$ Department of Chemistry, University of Gujrat, Gujrat-50700, Pakistan
}

(Received: November 17, 2010 - Accepted: October 6, 2010)

\begin{abstract}
In the present study conditions were optimized for the development and validation of a simple, sensitive and isocratic reverse phase high performance liquid chromatographic method for the simultaneous determination of ezetimibe and lovastatin in human plasma using gemfibrozil as internal standard. After a single step extraction with acetonitrile, satisfactory elution of both the analytes along with internal standard was achieved on a Merck C-18 column using a mixture of $0.1 \mathrm{M}$ ammonium acetate $\mathrm{pH} 5.0$ and acetonitrile in the ratio of $(28: 72, \mathrm{v} / \mathrm{v})$ at a flow rate of $1.5 \mathrm{ml} / \mathrm{min}$. The detection was carried out at a wavelength of $240 \mathrm{~nm}$ using a photodiode array detector. The method was linear in the concentration range of $0.2-25 \mu \mathrm{g} / \mathrm{ml}$ for ezetimibe and $0.4-50 \mu \mathrm{g} / \mathrm{ml}$ for lovastatin. The extraction recovery of analytes was greater than $85 \%$ and within day and between day precision was also satisfactory. The method was validated by performing its linearity, recovery, precision, LOD/LOQ values and stability of solutions. The total eluting time for the analysis is less than twelve minutes. As the plasma peaks did not interfere with the peaks of analytes so the method can be used for the determination of ezetimibe and lovastatin in human plasma and may possibly be for the pharmacokinetic study.
\end{abstract}

Key words: HPLC, plasma, diode array detector, gemfibrozil.

\section{1-INTRODUCTION}

Ezetimibe (Fig.1), a selective inhibitor of intestinal cholesterol and related phytosterol absorption, is designated as 1-(4-fluorophenyl)-3(R)-[3-(4fluorophenyl)-3(S)-hydroxypropyl]- 4(S)-(4-hydroxyphenyl)-2-azetidinone. Ezetimibe prevents transport of cholesterol through the intestinal wall by selectively blocking the absorption of cholesterol from dietary and billiary sources. This reduces the overall delivery of cholesterol to the liver, thereby promoting the synthesis of low density lipoprotein receptors and a subsequent reduction in serum low density lipoprotein cholesterol ${ }^{1-2}$. A variety of analytical methods have already been in the literature for ezetimibe either alone or in combination with other drugs ${ }^{3-12}$.

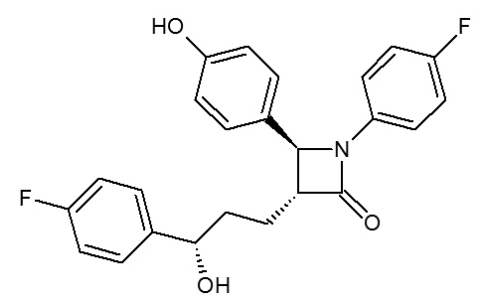

Fig. 1. Chemical Structure of Ezetimibe.

Lovastatin (Fig 2) designated as (1S,3R,7S,8S,8aR)-8-[2-[(2R,4R)-4hydroxy-6-oxotetrahydro-2Hpyran- 2-yl]ethyl]-3,7-dimethyl-1,2,3,7,8,8ahexahydronaphthalen-1-yl- (2S)- 2-methyl butanoate, is a cholesterol-reducing drug belonging to the family of statins and is widely used in the treatment of hypercholesterolemia ${ }^{13}$. Lovastatin is isolated from a Monascus and a strain of aspergillus terreus ${ }^{14-15}$. A number of analytical methods have already been published for the determination of Lovastatin in pharmaceutical formulations and in biological samples ${ }^{16-26}$. The combination therapy of ezetimibe with any statin is FDA approved and with this additional $12 \%$ to $21 \%$ absolute LDL cholesterol is reduced ${ }^{27}$. In a study conducted by Kerzner et al ${ }^{28}$, the coadministration of ezetimibe with lovastatin was shown to be more effective in decreasing plasma concentrations of LDL cholesterol than either lovastatin or ezetimibe alone. Ezetimibe $(10 \mathrm{mg})$ is therefore prescribed for reducing hyperlipidemia along with lovastatin $(20 \mathrm{mg})$. But unfortunately, according to the information collected from literature, no HPLC method has yet been published for the simultaneous determination of ezetimibe and lovastatin either in synthetic mixture or in human plasma so as to access their pharmacokinetic evaluation in combination form.

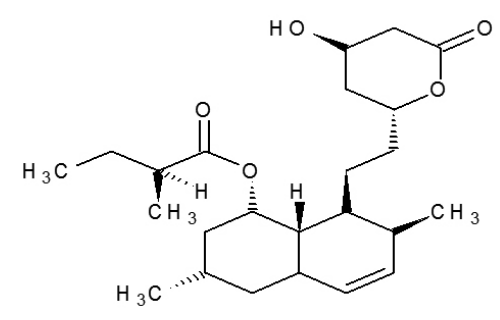

Fig 2. Chemical Structure of Lovastatin.

The present work is therefore aimed to attain the optimum chromatographic conditions for the simultaneous determination of ezetimibe and lovastatin in spiked human plasma.

We describe in this paper a simple, cheap, sensitive and validated HPLC method with retention time less than 12 minutes for the simultaneous determination of ezetimibe and lovastatin in spiked human plasma. The developed method can be successfully applied for the determination of these drugs in human plasma and may possibly be used for pharmacokinetic evaluation in human beings.

\section{2-EXPERIMENTAL}

\subsection{Chemicals and Reagents}

Reference standards of ezetimibe and lovastatin were obtained from Schazoo Laboratories (Lahore, Pakistan) and Xenon Pharmaceutical (Lahore, Pakistan). Acetonitrile (chromatography grade), ammonium acetate and acetic acid (analytical reagent grade) were purchased from Fluka (UK). Double distilled water was prepared in our laboratory using glass distillation apparatus. Before use, mobile phase was filtered through $0.45 \mu \mathrm{m}$ nylon filters from Millipore (USA). Whatman no. 41 filter papers (obtained commercially) were used in the preparation of sample solutions.

\subsection{Apparatus and chromatographic conditions}

A Shimadzu LC-20A system comprising a model LC-20AT pump, an SPD-M20A diode array detector, a CBM-20A interface module with class LC20 HPLC software, and a Rheodyne injection valve with a $20 \mu \mathrm{L}$ loop was used for development and evaluation of the method. Compounds were separated on a $250 \mathrm{~mm} \times 4.6 \mathrm{~mm}$ i.d., $5-\mu \mathrm{m}$ particle, Merck (UK) C 18 column. An internal standard method was used using gemfibrozil as an internal standard. Detection of the analytes was performed at $240 \mathrm{~nm}$. HPLC was operated at room temperature. Peak identity was confirmed by comparison of spectra and retention times with those of standards. 


\subsection{Preparation of mobile phase}

The mobile phase was prepared by mixing $0.1 \mathrm{M}$ ammonium acetate buffer $(\mathrm{pH}: 5.0)$ and acetonitrile in the ratio of 28:72 (v/v). The mobile phase was then filtered through $0.45 \mu \mathrm{m}$ nylon filters and degassed prior to use.

\subsection{Preparation of standard solutions}

The standard stock solution of lovastatin and ezetimibe was prepared by dissolving $20 \mathrm{mg}$ lovastatin and $10 \mathrm{mg}$ ezetimibe to a small amount of mobile phase in a $50 \mathrm{ml}$ volumetric flask and then raising the volume up to the mark with mobile phase. The final concentration thus achieved was equivalent to 400 $\mu \mathrm{g} / \mathrm{ml}$ and $200 \mu \mathrm{g} / \mathrm{ml}$ for lovastatin and ezetimibe respectively.

\subsection{Preparation of internal standard solutions}

The internal standard solution of gemfibrozil was prepared by dissolving $600 \mathrm{mg}$ gemfibrozil to a small amount of mobile phase in a $50 \mathrm{ml}$ volumetric flask and then raising the volume up to the mark with mobile phase. This provided a concentration of $12 \mathrm{mg} / \mathrm{ml}$.

2.6 Linearity

Linearity of the developed method was done by analyzing seven solutions in the range of $0.2-25 \mu \mathrm{g} / \mathrm{ml}(0.2,0.4,0.8,2.5,5,10,25 \mu \mathrm{g} / \mathrm{ml})$ for ezetimibe and $0.4-50 \mu \mathrm{g} / \mathrm{ml}(0.4,0.8,1.6,5,10,20,50 \mu \mathrm{g} / \mathrm{ml})$ for lovastatin. These different concentrations were made in plasma by adding appropriate volumes of the standard solution in seven different centrifuge tubes, each containing $1 \mathrm{ml}$ of plasma. $1 \mathrm{ml}$ of internal standard solution was then added in each tube, vortexed manually for 30 seconds, then $3 \mathrm{ml}$ acetonitrile in each tube was added and again vortexed for 3 minutes. The solutions were centrifuged for 10 minutes at 3500 RPM to precipitate the plasma protein. One half of the supernatant out of the total volume of solution was taken in a glass vial and evaporated it at $40{ }^{\circ} \mathrm{C}$ in incubator. To each vial, $2 \mathrm{ml}$ of mobile phase was added, dissolved by gentle shaking, filtered and analyzed immediately.

\subsection{Extraction Recovery}

To check the extraction recovery for lovastatin and ezetimibe, three concentrations from the linearity range were selected (Low, Medium, and High) and their results were compared with the results of un-extracted samples of same concentrations. Each sample was analyzed in triplicates and recovery was calculated in terms of $\%$ recovery.

\subsection{Precision}

The within-day and between-day precision was performed for the same three concentrations of samples as used for extraction recovery. For withinday precision samples were analyzed in triplicates within the same day and for between-day precision they were analyzed for consecutive three days and precision was expressed in terms of \% RSD.

\subsection{Limit of detection and quantitation}

Limit of detection is the decision point used to decide whether to report a significant analyte signal from the sample. It is usually measured when the signal to noise ratio is $3: 1$. Limit of quantitation is the lowest concentration of the analyte which can be quantified with accuracy and precision. It is measured when the signal to noise ration is 10:1. These limits were determined by analyzing the blank solution and the solutions with known progressively decreasing concentrations of analyte.

\section{RESULTS AND DISCUSSION}

In the present work attempts were made to develop a fast and efficient bioanalytical HPLC method for its possible use in pharmacokinetic studies. Before developing the method the main aim was to use simple chromatographic conditions, easier extraction of analytes from plasma and shorter retention time. Method development was started using ammonium acetate buffer $\mathrm{pH}$ 5.0 and acetonitrile in the ratio of 50: $50, \mathrm{v} / \mathrm{v}$ based on our previous method development for ezetimibe in combination with atorvastatin and simvastatin 4-5. At this composition, lovastatin, ezetimibe and internal standard gemfibrozil were efficiently eluted but the run time was more than 30 minutes. The mobile phase composition was then changed by increasing the organic phase stepwise to reduce the retention time. At the composition of 25:75 (buffer: acetonitrile), all the three components were eluted with retention time less than seven minutes. This composition was suitable for use in the analysis of synthetic mixture but when spiked human plasma was used, the plasma peaks interfered with the analyte peaks. The composition was then adjusted to separate the analyte peaks from plasma peaks. The final composition thus used was 28:72 (buffer: acetonitrile). Upon application of the proposed method, well separated sharp peaks were obtained for both ezetimibe and lovastatin along with internal standard within 12 minutes. The purpose of the work was to develop a simple HPLC method that could be used for any clinical study such as pharmacokinetic study. Unfortunately due to lack of facilities, the application of the method in pharmacokinetic studies or to some clinical studies could not be performed.
But we are hopeful that the method developed in spiked plasma can be used for any in-vivo studies. The represented chromatograms of ezetimibe, gemfibrozil and lovastatin are given in Figure 3.

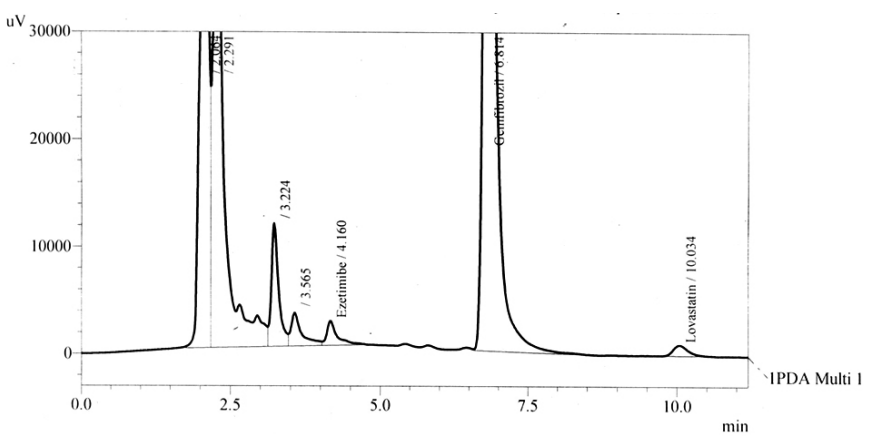

Figure. 3 Chromatogram showing lovastatin, ezetimibe and IS in plasma at LOQ.

The developed method was validated according to ICH guidelines. The validation parameters that were performed include linearity, precision, recovery, specificity, LOD/LOQ and stability of solutions.

The developed analytical method was linear in the concentration range of $0.2-25 \mu \mathrm{g} / \mathrm{ml}$ for ezetimibe and $0.4-50 \mu \mathrm{g} / \mathrm{ml}$ for lovastatin. Seven solutions were made for linearity for both ezetimibe and lovastatin in the range of $0.2-25$ $\mu \mathrm{g} / \mathrm{ml}(0.2,0.4,0.8,2.5,5,10$ and $25 \mu \mathrm{g} / \mathrm{ml})$ for ezetimibe and $0.4-50 \mu \mathrm{g} / \mathrm{ml}$ $(0.4,0.8,0.16,5,10,20$ and $50 \mu \mathrm{g} / \mathrm{ml})$ for lovastatin. The peak area ratio of drug to internal standard was plotted against the corresponding concentrations and a linear regression equation was calculated for each analyte along with the value of correlation coefficient. The method was linear in the mentioned ranges with linear regression equation $\mathrm{Y}=0.0568 \mathrm{X}-0.06892$ for ezetimibe and $\mathrm{Y}=0.026355 \mathrm{X}-0.11561$ for lovastatin. The correlation coefficient value was 0.9957 and 0.9956 for ezetimibe and lovastatin respectively.

The limit of detection (LOD) and limit of quantitation (LOQ) was calculated by analyzing a series of solutions with progressively decreasing concentration of each analyte. The limit of detection was then estimated at approximately about the concentration where there was a signal to noise ratio of $3: 1$. The limit of quantitation was calculated from the limit of detection by multiplying LOD with 3.3. The LOD values were found to be $0.06 \mu \mathrm{g} / \mathrm{ml}$ for ezetimibe and $0.12 \mu \mathrm{g} / \mathrm{ml}$ for lovastatin. The LOQ values were $0.2 \mu \mathrm{g} / \mathrm{ml}$ and $0.4 \mu \mathrm{g} / \mathrm{ml}$ for ezetimibe and lovastatin, respectively.

Recovery of lovastatin and ezetimibe from human plasma was calculated by analyzing three concentrations from the linearity range. These concentrations were $0.2 \mu \mathrm{g} / \mathrm{ml}$ (Low), $2.5 \mu \mathrm{g} / \mathrm{ml}$ (Medium) and $25 \mu \mathrm{g} / \mathrm{ml}$ (High) for ezetimibe and $0.4 \mu \mathrm{g} / \mathrm{ml}$ (Low), $5.0 \mu \mathrm{g} / \mathrm{ml}$ (Medium) and $50 \mu \mathrm{g} / \mathrm{ml}$ (High) for lovastatin. The peak areas obtained with these concentrations were then compared with the same concentrations but without human plasma. Each concentration was made and analyzed in triplicate. Similarly the extraction recovery of gemfibrozil was calculated by making three different solutions in plasma and comparing its results with the concentrations without plasma. The average recovery of ezetimibe and lovastatin was $90 \%$ and $86.5 \%$ respectively, whereas the average recovery of gemfibrozil was greater than $93 \%$. The extraction recovery values are given in Table 1.

Table 1. Extraction Recovery of Ezetimibe and Lovastatin from spiked human plasma.

\begin{tabular}{|lccccc|}
\hline Compound & $\mathrm{n}$ & $\begin{array}{c}\text { Actual Conc. } \\
(\mu \mathrm{g} / \mathrm{ml})\end{array}$ & $\begin{array}{c}\text { Measured Conc. } \\
(\mu \mathrm{g} / \mathrm{ml})\end{array}$ & $\begin{array}{c}\text { Recovery } \\
(\%)\end{array}$ & $\begin{array}{c}\text { RSD } \\
(\%)\end{array}$ \\
\hline Ezetimibe & 3 & 0.2 & 0.173 & 86.50 & 7.68 \\
& 3 & 5.0 & 4.67 & 93.40 & 6.39 \\
& 3 & 25.0 & 22.82 & 91.28 & 4.49 \\
Lovastatin & 3 & 0.4 & 0.332 & 83.00 & 8.08 \\
& 3 & 10.0 & 8.85 & 88.50 & 4.19 \\
& 3 & 50.0 & 44.02 & 88.04 & 3.34 \\
\hline
\end{tabular}


The precision of the method was calculated from the same solutions as used for extraction recovery. The within-day precision was evaluated by analyzing the three different concentrations of analytes each in triplicate within the same day and calculating their RSD. The between-day precision was evaluated by analyzing the same solutions for three consecutive days and calculating their RSD values. The results of the precision study are given in Table 2 .

Table 2. Within-day and Between-day precision of the proposed HPLC method.

\begin{tabular}{|lcccccc|}
\hline Compound & $\mathrm{n}$ & $\begin{array}{c}\text { Conc. } \\
(\mu \mathrm{g} / \mathrm{ml})\end{array}$ & \multicolumn{2}{c|}{ Within-day precision } & \multicolumn{2}{c|}{ Retween-day precision } \\
& & 0.2 & 0.17 & 7.49 & Mean & RSD $(\%)$ \\
\hline Ezetimibe & 3 & 0.16 & 9.89 \\
& 3 & 5.0 & 4.63 & 6.46 & 4.59 & 8.98 \\
& 3 & 25.0 & 22.62 & 4.89 & 22.02 & 6.04 \\
Lovastatin & 3 & 0.4 & 0.33 & 7.96 & 0.34 & 8.68 \\
& 3 & 10.0 & 8.83 & 4.38 & 8.75 & 5.39 \\
& 3 & 50.0 & 44.28 & 3.49 & 44.05 & 4.85 \\
\hline
\end{tabular}

The specificity of the method was performed by comparing the chromatograms of blank human plasma with the chromatograms of plasma spiked with analytes. The blank plasma peaks were well separated from the analytes peaks and hence method has fair selectivity or specificity. Figure 4 shows the blank plasma chromatograph.

Figure 4. Represented Chromatogram of blank human plasma, showing plasma peak

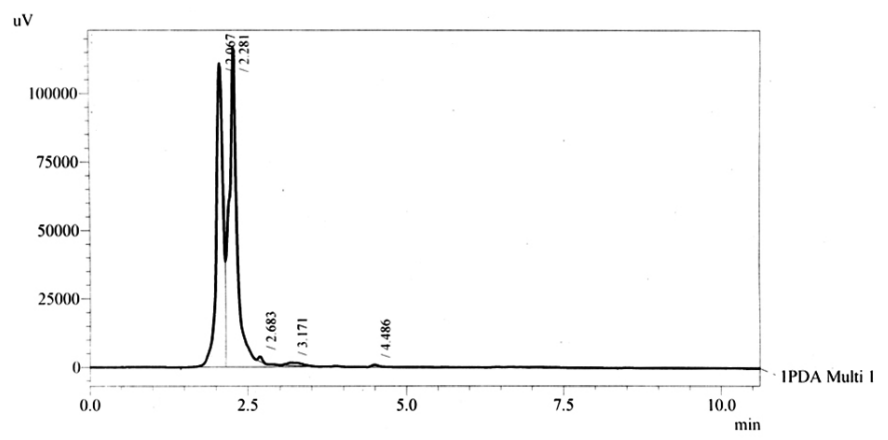

Stability of each analyte in the presence of the other and in the presence of internal standard was checked at three different temperatures i.e. at room temperature, at $4^{\circ} \mathrm{C}$ and at $-10^{\circ} \mathrm{C}$. Three different concentrations were used to evaluate the stability at each mentioned condition. The samples placed at room temperature were stable for at least 24 hours, whereas the samples stored at $4^{\circ} \mathrm{C}$ and at $-10^{\circ} \mathrm{C}$ were stable for at least seven days. There was no effect of consecutive freeze and thawing on the samples stored at $-10^{\circ} \mathrm{C}$. The results of stability study of both ezetimibe and lovastatin in spiked human plasma are given in Table 3 and 4.
Table 3. Stability study of ezetimibe in spiked human plasma.

\begin{tabular}{|c|c|c|c|c|c|c|}
\hline \multirow{3}{*}{$\begin{array}{l}\text { Conc. } \\
(\mu \mathrm{g} / \mathrm{ml})\end{array}$} & \multirow[t]{3}{*}{ Storage Condition } & \multicolumn{3}{|c|}{ Recovery \% of Concentration } & \multirow{3}{*}{$\begin{array}{l}\text { I } \\
\text { After } \\
36 \text { hours }\end{array}$} & \multirow{3}{*}{$\begin{array}{c}\text { Deviation } \\
\quad(\%) \\
\end{array}$} \\
\hline & & At & After & After & & \\
\hline & & Zero time & 12 hours & 24hours & & \\
\hline \multirow[t]{3}{*}{0.2} & Room Temp. & 86.50 & 85.59 & 84.69 & 82.01 & 5.19 \\
\hline & $4^{\circ} \mathrm{C}$ & 86.50 & 86.86 & 85.95 & 85.39 & 1.70 \\
\hline & $-10^{\circ} \mathrm{C}$ & 86.50 & 86.06 & 86.69 & 85.98 & 0.60 \\
\hline \multirow[t]{3}{*}{5.0} & Room Temp. & 93.40 & 91.55 & 90.05 & 89.89 & 3.76 \\
\hline & $4^{\circ} \mathrm{C}$ & 93.40 & 92.88 & 92.65 & 92.78 & 0.66 \\
\hline & $-10^{\circ} \mathrm{C}$ & 93.40 & 93.04 & 93.29 & 92.75 & 0.70 \\
\hline \multirow[t]{3}{*}{25.0} & Room Temp. & 91.28 & 89.74 & 88.99 & 88.04 & 3.55 \\
\hline & $4^{0} \mathrm{C}$ & 91.28 & 91.09 & 90.77 & 90.41 & 0.95 \\
\hline & $-10^{\circ} \mathrm{C}$ & 91.28 & 91.15 & 90.87 & 91.11 & 0.19 \\
\hline
\end{tabular}

Table 4. Stability study of lovastatin in spiked human plasma.

\begin{tabular}{|c|c|c|c|c|c|c|}
\hline \multirow{3}{*}{$\begin{array}{l}\text { Conc. } \\
(\mu \mathrm{g} / \mathrm{ml})\end{array}$} & \multicolumn{4}{|c|}{ Storage Condition Recovery $\%$ of Concentration } & \multicolumn{2}{|c|}{ Deviation } \\
\hline & & At & After & After & After & $(\%)$ \\
\hline & & Zero time & 12 hours & 24hours & 36 hours & \\
\hline \multirow[t]{3}{*}{0.4} & Room Temp. & 83.00 & 81.21 & 80.41 & 80.02 & 3.59 \\
\hline & $4^{\circ} \mathrm{C}$ & 83.00 & 82.84 & 82.05 & 81.86 & 1.37 \\
\hline & $-10^{\circ} \mathrm{C}$ & 83.00 & 82.89 & 82.54 & 82.65 & 0.42 \\
\hline \multirow[t]{3}{*}{10.0} & Room Temp. & 88.50 & 87.05 & 86.84 & 85.16 & 3.77 \\
\hline & $4^{\circ} \mathrm{C}$ & 88.50 & 88.12 & 87.58 & 87.02 & 1.67 \\
\hline & $-10^{\circ} \mathrm{C}$ & 88.50 & 88.31 & 87.98 & 87.55 & 1.07 \\
\hline \multirow[t]{3}{*}{50.0} & Room Temp. & 88.04 & 87.12 & 86.13 & 85.55 & 2.83 \\
\hline & $4^{0} \mathrm{C}$ & 88.04 & 87.58 & 87.15 & 86.98 & 1.20 \\
\hline & $-10^{\circ} \mathrm{C}$ & 88.04 & 87.89 & 87.58 & 87.32 & 0.82 \\
\hline
\end{tabular}

\section{4-CONCLUSION}

A validated HPLC analytical method was developed for simultaneous determination of ezetimibe and lovastatin in spiked human plasma. The validated method is accurate, precise, specific and reproducible for the determination of these drugs in human plasma and may possibly be used for pharmacokinetic studies. Therefore it is concluded that the developed method can be used for any in-vivo studies of these drugs in human beings.

\section{5- REFERENCES}

1. E. Leitersdorf. Int J Clin Pract., 56(2), 116 (2002)

2. M. Van Heek, C. Farley, D. S. Compton, L. Hoos, H. R. Davis. Br J Phamacol., 134, 409 (2001)

3. R. P. Dixit, C. R. Barhate, M. S. Nagarsenker. Chromatographia., 67, 101 (2008)

4. S. S. Qutab, S. N. Razzaq, I. U. Khan, M. Ashfaq, Z. A. Shuja. J Food Drug Anal., 15(2), 139 (2007)

5. M. Ashfaq, I. U. Khan, S. S. Qutab, S. N. Razzaq. J Chil Chem Soc. 52( 3), 1220 (2007)

6. N. Özaltın, E. Uçaktürk. Chromatographi., 66, 87 (2007) 
7. B. G. Chaudhari, N. M. Patel, P. B. Shah. J AOAC International, 90(5), 1242 (2007)

8. B. G. Chaudhari, N. M. Patel, P. B. Shah, L. J. Patel, V. P. Patel. J AOAC International, 90(6), 1539 (2007)

9. P. R. Oliveira, T. Barth, V. Todeschini, S. L. Dalmora. J AOAC International, 90(6), 1566 (2007)

10. S. J. S. Basha, S. A. Naveed, N. K. Tiwari, D. Shashikumar, S. Muzeeb, T. R. Kumar, N. V. Kumar, N. P. Rao, N. Srinivas, R. Mullangi, N. R. Srinivas. J Chromatography B. 853, 88 (2007)

11. S. Singh, B. Singh, R. Bahuguna, L. Wadhwa, R. Saxena. J Pharm Biomed Anal., 41(3), 1037(2006)

12. R. Sistla, V.S. Tata, Y. V. Kashyap, D. Chandrasekar, P. V. Diwan. J Pharm Biomed Anal., 39(3-4), 517 (2005)

13. P. O'Connor, J. Feely, J. Shepherd. BMJ, 300, 667 (1990)

14. A. Endo, K. Monacolin. J Antibiotics. 32, 852(1979)

15. A. W. Alblerts, J. Chen, G. Karonl. J Proc Natl Acad Sci USA. 77, 3957(1980)

16. D. Wang, D. Wang, F. Qin, L. Chen, F. Li. Biomed Chromatogr. 22(5), $511(2008)$

17. H. Yuana, F. Wanga, J. Tua, W. Penga, L. Huande. J Pharm Biomed Anal., 46(4), 808 (2008)
18. X. R. Yu, M. Sondi, T. J. Hangi, A. D. Wen. Acta Chromatographica. 20, $399(2008)$

19. Z. Zhang, Z. Yang. Chromatographia. 66, 487 (2007)

20. L. Min, L. Fan, W. Zhang, C. Cao. Anal Bioanal Chem. 387, 2719 (2007)

21. A. Álvarez-Lueje, J. Pastine, J. A. Squella, L. J. Nunez-Vergara. J. Chil. Chem. Soc. 50(4), 639 (2005)

22. M. G. Orkoula, C. G. Kontoyannis, C. K. Markopoulou, J. E. Koundourellis. J Pharm Biomed Anal. 35(5), 1011 (2004)

23. P. Sharma, H. Chawla, R. Panchagnula. J Chromatogr B. 768(2), 349 (2002)

24. L. Y. Ye, P. S. Firby, M. J. Moore. Ther Drug Monit. 22(6), 737 (2000)

25. J. T. Strode, L. T. Taylor, A. L. Howard, D. Ip. J Pharm Biomed Anal. 20(1-2), 137(1999)

26. D. J. Mazzo, S. E. Biffar, K. A. Forbes, C. Bell, M. A. Brooks. J Pharm Biomed Anal. 6(3), 271 (1988)

27. L. Jeu, J. W. Cheng. Clin Ther. 25, 2352 (2003)

28. B. Kerzner, J. Corbelli, S. Sharp, L. J. Lipka, L. Melani, A. LeBeaut, R. Suresh, P. Mukhopadhyay, E. P. Veltri. Am J Card. 91, 418 (2003) 